\title{
Operation of Resonant DC/DC Converter in the BUCK Operation Regime
}

\author{
Ivars Rankis ${ }^{1}$, Janis Zakis ${ }^{2},{ }^{1-2}$ Riga Technical University
}

\begin{abstract}
The series resonant DC/DC converter with isolation transformer is investigated. When switching frequency of input inverter bridge is above the resonant one a shortening of the naturally half-waves of current through a $\mathrm{L}-\mathrm{C}$ resonant circuit takes place resulting in a circulating current through the DC supply source reducing a mean value of supply current and also reducing load voltage in respect to the one at normally resonant case. The main relations for the case with strong voltage supply source are obtained and operation regimes at raised switching frequency investigated using a computer modeling. Some conclusions are made for proper calculation of parameters. It is shown that the shape of the resonant circuit current at raised frequency grows to the triangular one and that asks for proper correction of the expressions obtained for sinusoidal case. Applying qZ input link processes quite differ from observed for the strong supply - arise charging of the capacitors of the link by influence of circulating current and this phenomena impedes to reducing of the load voltage. That $\mathrm{qZ}$ link does not allow to create proper regulation of load parameters.
\end{abstract}

Keywords - BRIDGE, capacitor, coil, commutator, frequency, inverter, switch, transformer, transistor.

\section{INTRODUCTION}

The paper [1] proposes to introduce in supply circuit of the DC/DC series resonant converter the qZ circuit $[2,3,10,11,12]$ which allows to obtain operation of an inverter-based converter as in BOOST as well in BUCK operation regimes. At that the later should be provided increasing a control switching frequency above the resonant one which depends on the accepted values of the resonant circuit inductance $\mathrm{L}$ and series resonant capacitor $\mathrm{C}$ $[3,4,5,6]$. A good methodology of investigation of the resonant converters is presented in $[7,8,9]$ but without the $\mathrm{qZ}$ link. Because of the novelty of the proposed solution a certain evaluation of the method must be done and that is the purpose of the paper.

\section{CIRCUIT UNDER EXAMINATION}

The scheme of the DC/DC converter presented in Fig. 1 with DC source qZ circuit, bridge mode transistors' commutator, LC resonance circuit in the primary winding of an insulating transformer with secondary winding introduced in the voltage doubling rectifier operating on voltage smoothing capacitor by-passed load, is under examination. Sources $[1,2,3]$ show that such converter can operate as in so named normal regime at switching frequency equally to the resonant one, in the BOOST case at the same control frequency and in the BUCK case when output voltage of the load can be regulated below value corresponding to the normal one. At that later can be applied an increasing frequency of switching $\omega_{s w}$ that shortening the normal resonant current halfwave determined by the parameters of the resonant circuit $\omega_{r}$ $[1,2]$.

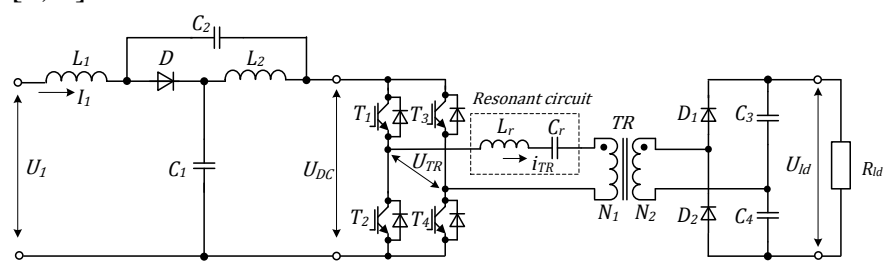

Fig. 1. The principal scheme of the converter investigated.

\section{The CIRCUlating CURRENT PROCESSES}

In the case an operating pairs of the commutator's switches are turned-off before the end of the half-cycle of resonant current $i_{T R}$ (in the Fig. 2, for instance, switch pair T1, T4 is turned-off at $i_{T R}>0$ and at the same instant the pair T2, T3 is activated). Because of that the instant direction of resonant circuit current is opposite to the conductivity direction of the turned-on transistors then current $i_{T R}>0$ for some angular interval $\varphi$ is passing through a reverse diodes of the activated switch pair and is decreasing faster under the influence of the reverse supply voltage across output $u_{T R}$ of the commutator's bridge (Fig. 2). Current of the supply DC source $i_{1}$ in the interval $\varphi$ is changing its direction to the negative, i.e. in the source the circulating current arises decreasing an average meaning of the supply current and also the power supplied from source. With that the load voltage is also decreasing respectively.

\section{SIMPLIFIED MATHEMATICAL DESCRIPTION OF THE PROCESSES}

First of all let us assume that dc source is "strong" one, i.e. with voltage source characteristics. For description of processes for converter at circulating current of very special significance is duration of the circulation in the half-cycle of switching process. With very large approximation it should be accepted that the current of resonant circuit is of sine-shape and then shift angle $\varphi$ between input AC voltage $u_{T R}$ and current of the resonant circuit $i_{T R}$ at lagging current in respect to the voltage can be applied for the calculation of power transmitted to the load circuit

$$
P=U_{\text {inrms }} I_{\text {TRrms }} \cos \varphi=\frac{4 U_{1}}{\pi \sqrt{2}} \cdot \frac{I_{\text {TRm }}}{\sqrt{2}} \cos \varphi .
$$




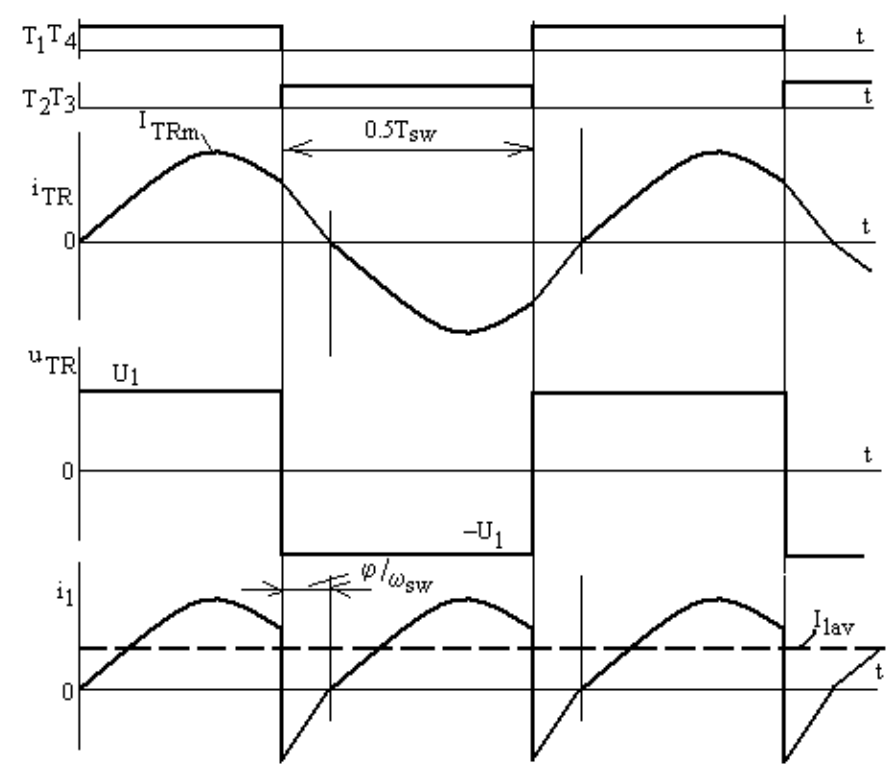

Fig. 2. Diagrams of currents and voltages for BUCK operation regime.

Here an RMS of the fundamental of the input square AC voltage $u_{\mathrm{TR}}$ is accepted as input voltage. From other side power can be calculated through the load voltage and resistance. In the examined circuit the amplitude of current through the resonant circuit is directly connected with averaged meaning of the load voltage:

$$
U_{l d}=\frac{R_{l d} I_{T R m} k_{T R}}{\pi}
$$

where $k_{\mathrm{TR}}$ is turns ratio of transformer's windings $N_{1} / N_{2}$.

Then the shift angle which defines the duration in the switching half-cycle of a circulating through the voltage source DC supply current can be determined as

$$
\varphi=\arccos \frac{I_{T R m} k_{T R}^{2} R_{l d}}{2 \pi U_{1}}
$$

but time duration for the circulating current is

$$
t_{1}=\frac{\varphi}{\omega_{s w}} .
$$

As it can be seen the duration depends on the amplitude of current through resonant circuit - for larger amplitude the smaller duration. The larger amplitudes are close to the resonant frequency when shorter circulating durations take place. But for really application of the expression for the angle it needs to know the amplitude of current through resonant circuit which is not defined at initial calculations.

As the impedance of LC circuit is rising practically in same extent with switching frequency $f_{s w}$ rising up from resonant one $f_{r}$ it can be accepted that the amplitudes of current through resonant circuit at the VS mode supply change at it in reverse mode to one at resonant frequency:

$$
I_{T R m}=I_{T R m r} \frac{f_{r}}{f_{s w}} .
$$

As angle $\varphi$ at $f_{s w}=f_{r}$ is equal to zero the amplitude of current $i_{T R}$ for the case can be calculated as

$$
I_{T R m r}=\frac{2 \pi U_{1}}{k_{T R}^{2} R_{l d}} .
$$

Introducing the relative meaning

$$
\omega_{s w}^{*}=\omega_{s w} / \omega_{r}>1
$$

the circulation time interval can be expressed as

$$
t_{1}=\frac{1}{\omega_{s w}} \arccos \frac{I_{T R m} k_{T R}^{2} R_{l d}}{2 \pi \omega_{s w}^{*} U_{1}} ;
$$

the load voltage the following

$$
U_{l d}=\frac{R_{l d} I_{T R m l} k_{T R}}{\pi \omega_{s w}^{*}} .
$$

The angle $\varphi$ in its turn determines relation between averaged meaning of supply current $\mathrm{I}_{1 \mathrm{av}}$ and an amplitude of current in the resonant circuit $I_{\mathrm{TRm}}$ (as it was said it is accepted that current is of sine-wave):

$$
\begin{aligned}
& I_{1 a v}=\frac{1}{\pi \cdot \omega_{s w}^{*}}\left[\int_{0}^{\pi-\varphi} I_{T R m r} \sin \vartheta d \vartheta-\int_{\pi-\varphi}^{\pi} I_{T R m r} \sin \vartheta d \vartheta\right]= \\
& =\frac{2 I_{T R m r}}{\pi \omega_{s w}^{*}} \cos \varphi=\frac{4 U_{1}}{k_{T R}^{2} R_{l d} \omega_{s w}^{*}}
\end{aligned}
$$

where $\vartheta=\omega_{s w} t$.

If losses in the resonant circuit could be defined with substitution resistance $R_{1}$ then for loss-less supply a balance of the powers can be presented as

$$
U_{1} I_{1 a v}=\frac{U_{l d}^{2}}{R_{l d}}+\frac{I_{T R m}^{2} R_{1}}{2}=I_{T R m}^{2}\left(\frac{R_{l d} k_{T R}^{2}}{\pi^{2} \omega_{s w}^{* 2}}+0.5 R_{1}\right) .
$$

Introducing expressions $(7,10)$ yields that an amplitude of current in resonant circuit with resistance is

$$
I_{T R m}=\frac{2 U_{1} \pi \sqrt{\omega_{s w}^{*}}}{k_{T R} \sqrt{R_{l d}^{2} k_{T R}^{2}+0.5 \pi^{2} R_{1} R_{l d} \omega_{s w}^{* 2}}},
$$

but load voltage is

$$
U_{l d}=\frac{2 U_{1} R_{l d} \sqrt{\omega_{s w}^{*}}}{\omega_{s w}^{*} \sqrt{R_{l d}^{2} k_{T R}^{2}+0.5 \pi^{2} R_{1} R_{l d} \omega_{s w}^{* 2}}} .
$$

Amplitude of voltage across capacitor of resonant circuit can be calculated as

$$
U_{c m}=I_{T R m} \sqrt{\frac{L}{C}} .
$$

\section{VERIFICATION OF THE EXPRESSIONS}

Fig. 3 presents the calculated curves of load voltage, resonant circuit current and supply current in the dependence on $\omega_{s w}^{*}$ at voltage of the ideal supply voltage $50 \mathrm{~V}$, transformer's turns ratio 1:6, parameters of a resonance circuit $L=14.5 \mu \mathrm{H}$, $C=3.0 \mu \mathrm{F}$ operating with voltage doubler load rectifier. In the case when resonant frequency is $24145 \mathrm{~Hz}$ and load voltage for switching with resonant frequency is $600 \mathrm{~V}$, amplitude of current through the resonant circuit is $56.5 \mathrm{~A}$, but supply current $36 \mathrm{~A}$. 


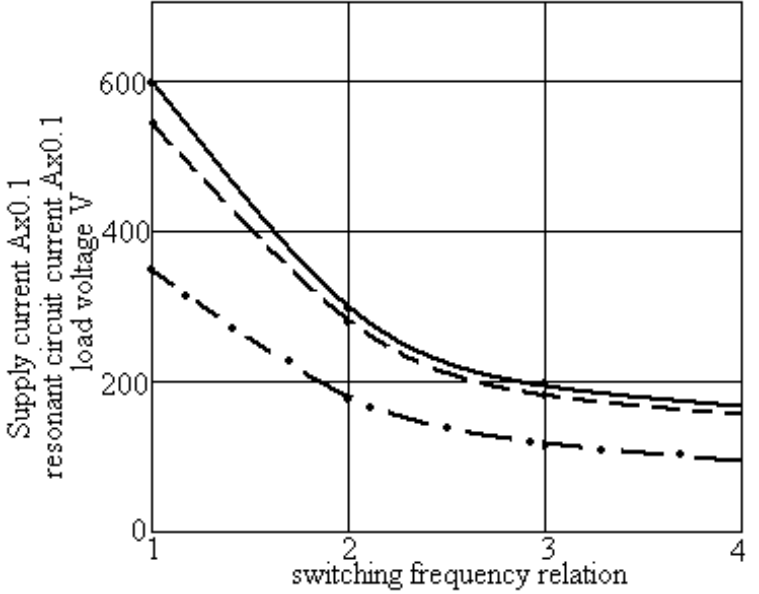

Fig. 3. Calculated curves of the load voltage, resonant circuit current amplitude (dashed) and supply averaged current (dash-dotted) depending on relation of switching frequency to the resonance one.

Computer simulations show that at rising of switching relation $\omega_{s w}^{*}$ a shape of current differs a lot from the sine-wave form - it is closer to the triangular one (see Fig. 4)
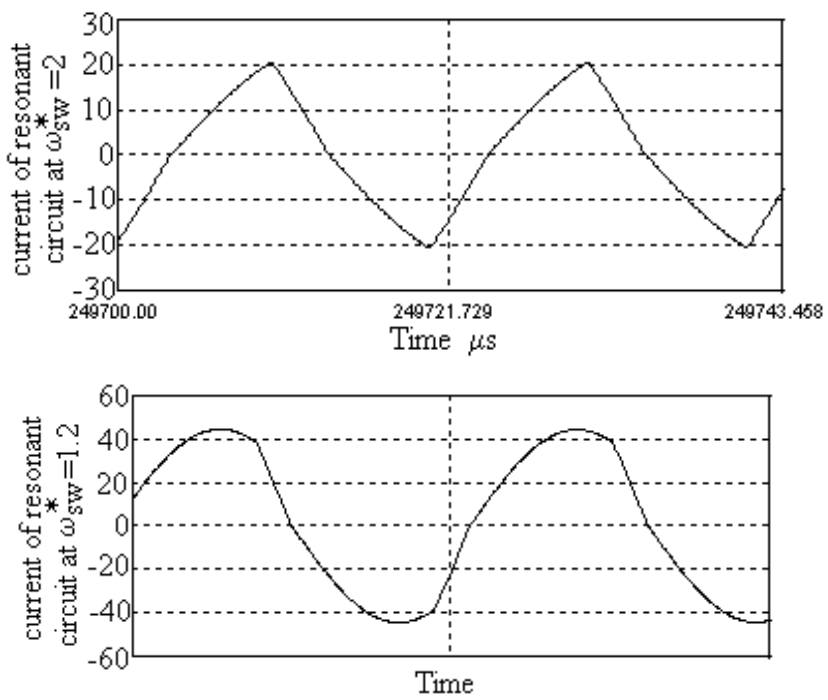

Fig. 4. Simulated diagrams of current in resonant circuit at $\omega_{s w}^{*}=2$ (above) and $\omega_{s w}^{*}=1.2$ for parameters before mentioned.

As a result at rising of $\omega_{s w}^{*}$ voltage of load, current of resonant circuit and supply one differs from calculated using expressions obtained before (see Fig. 5).

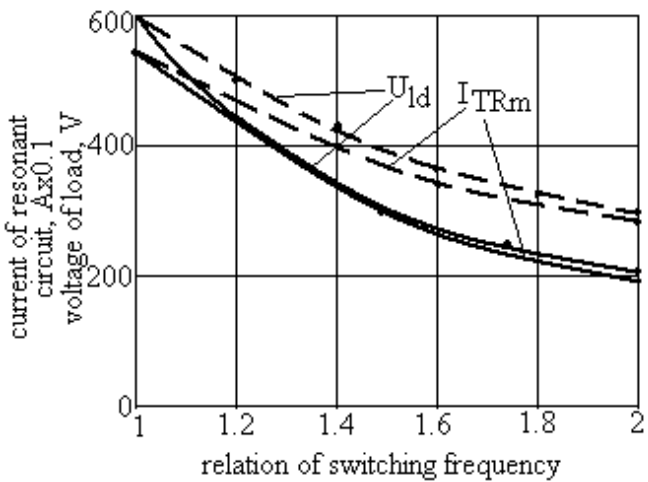

Fig. 5. Simulated (bold) and calculated (dashed) values of load voltage and current of resonant circuit.
As it can be seen the simulated values of load voltage and load current with rising of switching frequency relation are below the calculated ones when using previously obtained expressions. That is the reflection of changing of a shape of the current in resonant circuit. For more accurate calculation of the character of the processes the expression of the amplitude of current of resonant circuit should corrected:

$$
I_{T R m}=\frac{I_{T R m r}\left[1-0.3\left(\omega_{s w}^{*}-1\right)\right]}{\omega_{s w}^{*}} .
$$

Then load voltage can be calculated using (2) but averaged current of the supply as

$$
I_{1 a v}=\frac{U_{l d}^{2}}{U_{1} R_{l d}} .
$$

Taking into account correction of the amplitude of resonant current the circulation time interval can be calculated as

$$
t_{1}=\frac{1}{\omega_{s w}} \arccos \frac{I_{T R m} k_{T R}^{2} R_{l d}}{2 \pi U_{1}}
$$

but angle $\varphi_{1}=\arccos \frac{I_{T R m} k_{T R}^{2} R_{l d}}{2 \pi U_{1}}$. Fig. 6 presents $t_{1}$ and $\varphi_{1}$ in relation to switching frequency calculated in accordance with the last expressions.

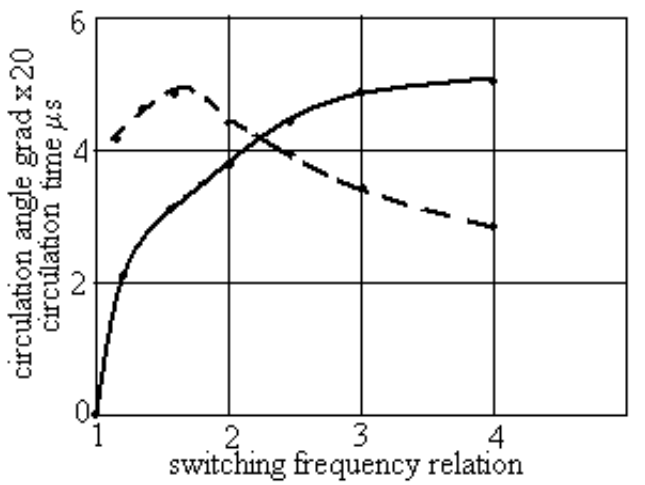

Fig. 6. Calculated dependencies of current circulation time (dashed) and circulation angle on relation of switching frequency $\omega_{s w}^{*}$.

As it can be seen a current circulation time is almost constant but circulation angle is rising almost exponentially.

Regarding to the voltage of capacitor, this indicator also could not be calculated at high frequencies in the scheme at changed to the triangular shape of current in the resonant circuit. Applying the triangular shape of current the amplitude of voltage can be calculated as a product of approximately time duration of switching half-cycle and a fourth of the amplitude of current in resonant circuit over capacitance of the resonant circuit:

$$
U_{C m}=I_{T R m r} \frac{0.6\left[1-0.3\left(\omega_{s w}^{*}-1\right)\right]}{4 \omega_{s w}^{*} f_{s w} C} .
$$

As it can be seen at rising of $\omega_{s w}^{*}$ an amplitude of voltage across capacitor plates is decreasing. For instance if at resonant case for parameters applied in previous calculation patterns by (16) the voltage $U_{C m r}=119 \mathrm{~V}$, then at $\omega_{s w}^{*}=1.9$ it decreases to $20 \mathrm{~V}$ which well complies simulation results. 


\section{OPERATION WITH INPUT QZ JUNCTION}

Input qZ junction comprising coils $L_{1}$ and $L_{2}$, capacitors $C_{1}$ and $C_{2}$ as also the diode $D$ (see Fig. 1) is used in circuit of DC supply source for provision of operation of switching converters as in BUCK as well in the BOOST mode $[1,2,10,11]$. At the later periodically shortening of converter legs named as shoot-through cycles can be applied increasing in result voltage at output of a qZ link $[2,10]$.

Really at BUCK operation case introduction of the link the voltage source properties of the DC supply circuit are weaken and therefore normally circulation of supply current as well changes of current through resonant circuit partially are disturbed. It is connected with that the average currents of the both qZ link coils are same and equal to the mean value of supply source $I_{1 \text { av }}$. Therefore with rising of circulating currents and increasing switching frequency $f_{s w}$ and weakening of the supply current at certainly large frequency $f_{s w}$ a limitation of $2 I_{1 \text { av }}$ is applied to the current of resonant circuit. If the current of resonant circuit grows to the limitation value then the voltage across the coil of resonance circuit falls to zero value and input voltage of the switch bridge $u_{D C}$ (see Fig. 1) becomes equal to the sum of resonant capacitor $C$ and primary winding of the transformer voltages, which in the time interval when resonant current is limited is below the value of supply voltage $U_{1}$ (Fig. 7), i.e. pseudo-shortening of switch bridge input takes place arising the $u_{D C}$ value in current interval connected with passing of charging current in time interval $t_{D}$ through the separating diode $D$ of the qZ link. With the latter the input voltage $u_{D C}$ is equal to a sum of voltages of the both qZ link capacitors and should be above the value of supply voltage $U_{1}$.

Taking into account (2) and the expression for corrected resonant current amplitude (15) it can be stated that an order for arising of resonant current limitation takes place at switching frequency relation

$$
\omega_{s w B}^{*}=\frac{2.6 \cdot I_{T R m r} R_{l d} k_{T R}^{2}}{\pi^{2} U_{1}+0.6 I_{T R m r} R_{l d} k_{T R}^{2}} .
$$

For instance at the parameters applied for the previous example such limitation of current through resonant circuit starts at $\omega_{s w B}^{*}=1.18$, i.e. at switching frequency $f_{s w}=28491 \mathrm{~Hz}$ which very well complies with the results obtained at computer simulation.

Approximately an average current of DC supply source can be obtained when current in the resonant circuit in a half-cycle of processes is accepted as trapezoidal with time length of the shorter upper side as $\left(0.5 T_{\mathrm{sw}}-t_{D}\right)$. Then load voltage in the scheme can be expressed as

$$
\begin{aligned}
& U_{l d B}=I_{1 a v} k_{T R} R_{l d} \frac{0.5 T_{s w}-t_{D}+0.5 T_{s w}}{2 \cdot 0.5 T_{s w}}= \\
& =I_{1 a v} k_{T R} R_{l d}\left(1-t_{D} f_{s w}\right)
\end{aligned}
$$

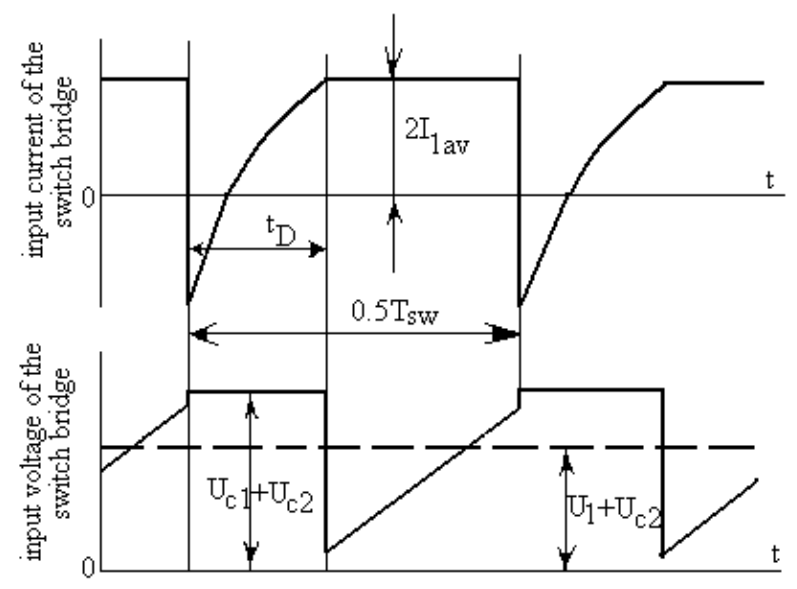

Fig. 7. Diagrams of input current and input voltage of the switch bridge at operation with the qZ link and sufficiently high a switching frequency.

In its turn the average current of supply source can be expressed as

$$
I_{1 a v B}=\frac{U_{l d}^{2}}{R_{l d} U_{1}}=\frac{U_{1}}{k_{T r}^{2} R_{l d}\left(1-t_{D} f_{s w}\right)^{2}}
$$

and expression for load voltage can be expressed as

$$
U_{l d B}=\frac{U_{1}}{k_{T R}\left(1-t_{D} f_{s w}\right)} .
$$

Time interval for circulation of qZ link capacitors charging current through the diode $D$ (see Fig. 1) can be estimated by linearization in time a slope rising front of the current through resonant circuit (see Fig. 7). The shape of this current defines a current through qZ link capacitor $C_{2}$ an averaged meaning of which is zero. Taking into account that if the capacitor's current is rising in $t_{D}$ interval from $-3 I_{1 \text { av }}$ to the $0.5 T_{s w}$ the length of the interval can be expressed as

$$
t_{D}=0.25 T_{s w} \text {. }
$$

Then the equations component $\left(1-t_{D} f_{s w}\right)=0.75$, i.e. it is constant. Therefore a conclusion can be made stating that load voltage at switching frequencies above the boundary frequency $\left(\omega_{s w B}^{*} \omega_{r}\right)$ really is constant as it is also a supply source averaged current.

At the example applied for calculations at switching frequencies above the boundary frequency the load voltage calculated by (19) is $400 \mathrm{~V}$, but averaged value of supply current is $16 \mathrm{~A}$.

\section{SIMULATION OF OPERATION PROCESSES}

For evaluation of calculation patterns a simulation of the scheme at parameters applied for calculations a computer simulation has been made. Applying the qZ link has been adopted that $L_{1}=L_{2}=0.4 \mathrm{mH}, C_{1}=C_{2}=0.2 \mathrm{mF}$ but load voltage smoothing capacitors are $3 \mathrm{mF}$ each.

Simulated diagrams when operating with voltage source supply of $50 \mathrm{~V}$ are presented in Fig. 8, but with qZ link in Fig. 9. In the both cases switching frequency were accepted as $f_{s w}=46145 \mathrm{~Hz}$, i.e. almost 1.9 time higher as the resonant 
frequency is for the link parameters adopted for calculation patterns.

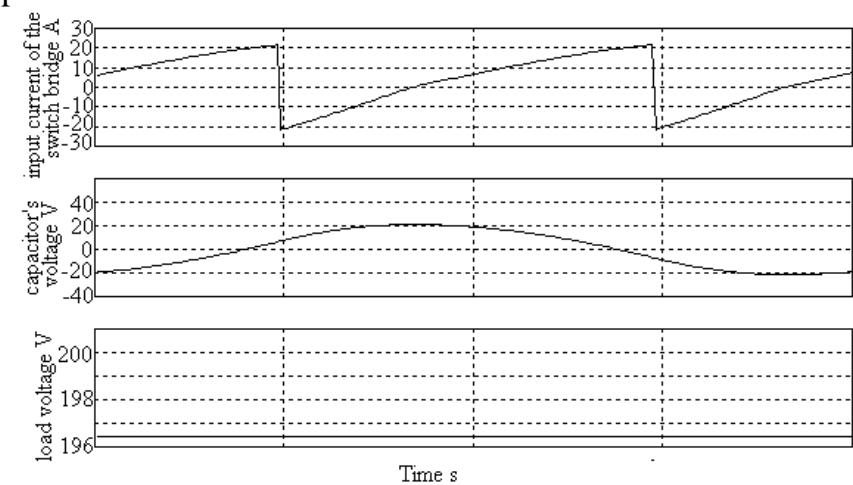

Fig. 8. Simulated diagrams of current and voltages for the scheme operating with strong voltage source supply.

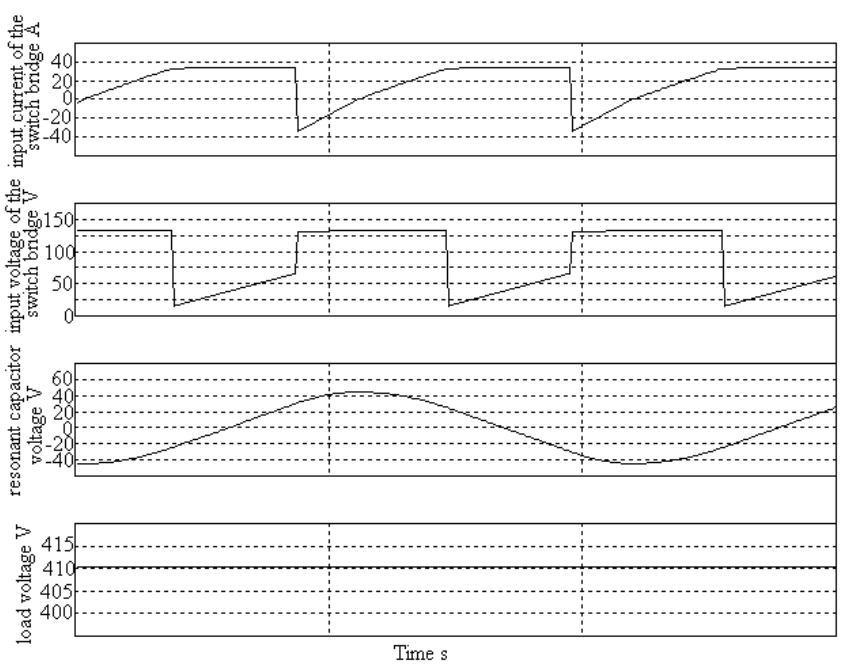

Fig. 9. Simulated diagrams of voltage and current in elements of the scheme at applying of qZ input link and switching frequency $46145 \mathrm{~Hz}$.

As it can be seen from the both diagrams the shapes of current through resonant circuit are different - for case without qZ link it is close to triangular one but for the case with qZ link - trapezoidal with the upper side on level of $33 \mathrm{~A}$. A shape of switch bridge input voltage in the case with the $\mathrm{qZ}$ link is with periodically time intervals below value of supply voltage and similarly - above the supply voltage when presenting a summary voltage of the both capacitors of qZ link, which in the case reaches up to $135 \mathrm{~V}$, rising up also averaged value of the input voltage up to $80 \mathrm{~V}$. Therefore the load voltage with qZ link is above the value obtained for the strong supply source - for the scheme with qZ link it is $410 \mathrm{~V}$, but for the strong supply source - about $196 \mathrm{~V}$.

The changes of load voltages for the parameters accepted previous with change of frequency as well as the changes of supply current, an amplitude of the resonant capacitor voltage and amplitude of current in resonant circuit are presented in Fig. 10.

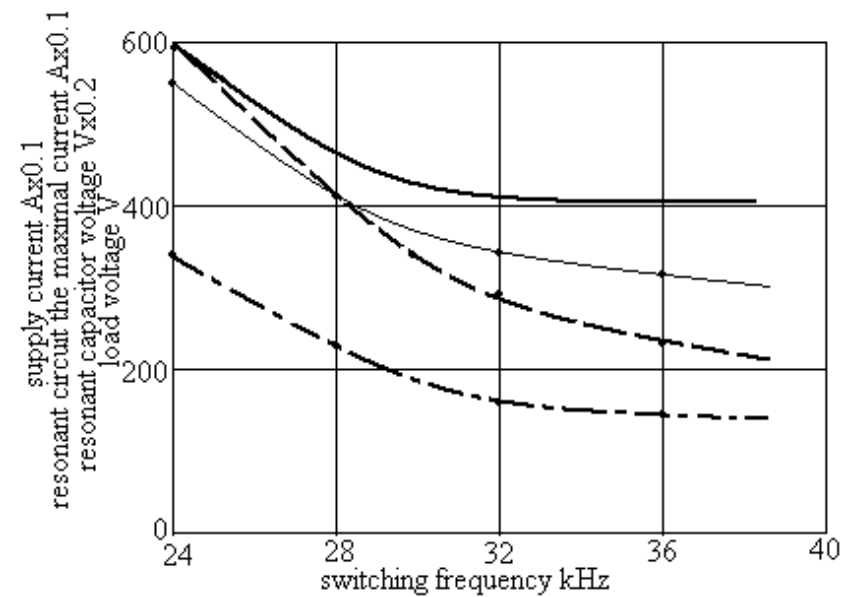

Fig. 10. Dependence of load voltage (bold line), an amplitude voltage of the resonant capacitor (dashed line), an amplitude of current in the resonant circuit (thin line) and supply current (point-dashed line) on switching frequency at operation with qZ input link.

As it can be seen the load voltage at initial rise of the switching frequency decreases similarly as it was in the case with strong DC supply but starting at frequency about $29 \mathrm{kHz}$ a decrease temp is softened and at higher frequencies decrease process is stopped at all. Similarly is changing also DC supply current which at arising of circulated current becomes about twice smaller as it's the maximal instantaneous value of current in the resonant circuit. Much faster the amplitude of the resonant capacitor voltage is decreasing.

\section{CONCLUSIONS}

1. At strong DC supply source the increasing of switching frequency of the inverter bridge above the resonant value results in the forming of circulated current, decreasing the load voltage as well as the amplitude of current in resonant circuit and supply current. With that the form of the resonant circuit current gradually changes from the sinusoidal to the triangular one.

2. Because of the resonant current shape change an obtained expressions for calculation of parameters of the processes have to be corrected to achieve faster decreasing of the calculated fundamental operation parameters. Verification of the expressions has shown a sufficiently high accuracy.

3. Introduction of the $\mathrm{qZ}$ input DC supply link brings to crucial change of the characteristics of processes - with the increasing of the switching frequency the circulating currents provide an extra charge to the voltages of $\mathrm{qZ}$ link capacitors and as a result the decrease of load voltage, supply current and an amplitude of current through resonant circuit is mitigated. The amplitude of current in resonant circuit is restricted to the doubled meaning of supply current.

\section{ACKNOWLEDGMENT}

This research work has been supported by Latvian Council of Science (Grant 416/2012). 


\section{REFERENCES}

[1] J. C. Rosas-Caro, F. Z. Peng, H. Cha, and C. Rogers, ZSourceConverter-Based Energy-Recycling Zero-Voltage Electronic Loads, IEEE Transactions on Industrial Electronics, vol. 56, no. 12, pp. 4894-4902, Dec., 2009. http://dx.doi.org/10.1109/TIE.2009.2026374

[2] J. Anderson and F. Z. Peng, A Class of Quasi-Z-Source Inverters, in Industry Applications Society Annual Meeting, 2008, pp. 1-7. http://dx.doi.org/10.1109/08IAS.2008.301

[3] L. Yuan, J. Anderson, F. Z. Peng, and L. Dichen, Quasi-Z-Source Inverter for Photovoltaic Power Generation Systems, in Proc. IEEE APEC 2009, Applied Power Electronics Conference and Exposition, 2009. pp. 918-924. http://dx.doi.org/10.1109/APEC.2009.4802772

[4] N. D. Ludu, Basic operating characteristics of a high-frequency inverter wth capacitive voltage multiplier, ZEEE Trans. Industry Applications, vol. IA-14, no. 3, pp. 264-269, May/June, 1978. http://dx.doi.org/10.1109/TIA.1978.4503532

[5] V. T. Ranganathan, P. D. Ziogas, and V. R. Stefanovic, A generalized approach for the steady state analysis of resonant inverters, ZEEE Trans. Industry Applications, vol. 25, no. 2, pp. 326-338, Mar./Apr. 1989. http://dx.doi.org/10.1109/28.25549

[6] V. T. Ranganathan, P. D. Ziogas, and V. R. Stefanovic, A regulated dc-dc voltage source converter using a high-frequency link, IEEE Trans. Industry Applications, vol. IA-18, no. 3, pp. 279-287, May/June 1982. http://dx.doi.org/10.1109/TIA.1982.4504075

[7] R. L. Steigerwald, High-frequency resonant transistor dc-dc converters, ZEEE Trans. Znd. Electron., vol. IE-31, no. 2, pp. 181-191, May, 1984. http://dx.doi.org/10.1109/TIE.1984.350066

[8] A. K. S. Bhat, A Unified Approach for the Steady-State Analysis of Resonant Converters, IEEE Transactions on Industrial Electronics, vol. 38, no. 4, August, 1991. pp. 251-259. http://dx.doi.org/10.1109/41.84018

[9] Kai Xu. A series-parallel resonant topology and new gate drive circuits for low voltage de to de converter. Thesis Dep. of Electr. and Comp. Engin., Queen's University, Kingston, Ontario, Canada. Jan., 2008, pp. 166.

[10] D. Vinnikov, J. Zakis, L. Liivik, I. Rankis, qZS-Based Softswitching DC/DC Converter with a Series Resonant LC Circuit. Energy saving, power, power audit, vol. 2, no. 8 (114), 2013. pp. 42-50. (in Russian).

[11] J. Zakis, D. Vinnikov, O. Husev and I. Rankis, Dynamic Behaviour of qZS-Based Bi-Directional DC/DC Converter in Supercapacitor Charging Mode, International Sympos. on Power Electron., Electr. Drives, Automation and Motion (SPEEDAM 2012): Conference Publications, Italia, Sorento, 20.-22. June, 2012. pp. 764.-768. http://dx.doi.org/10.1109/SPEEDAM.2012.6264554

[12] I. Rankis, J. Zakis, Investigation of Supercapacitor Bidirectional Power Flow System. Power and Electrical Engineering, Riga, RTU, vol. 30, 2012, pp. 35-40.

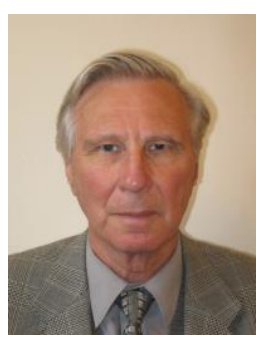

Ivars Rankis, professor, Dr. habil. sc. ing. He graduated from Riga Polytechnical institute in 1960 as engineer-electromechanic. Defended his first degree of Dr. Sc. (candidate of technical sciences) in 1970. Defended his second degree Dr. habil. sc. ing. in 1992 at Riga Technical University. From 1958-1966 he worked as engineer at Riga Electrical machine building company. From 1966 he started studies as doctoral student, but from 1970 - as teacher of different subjects of electrical engineering at Riga Technical University. Research interests are connected with Power electronics and Industrial automation. Now is professor at departement of Industrial electronics and electrical technologies of Riga Technical University. Riga Technical University, Institute of Industrial Electronics and Electrical Engineering.

Address: Kronvalda 1, LV-1048, Riga, Phone +371 67089 917;

E-mail: rankis@eef.rtu.lv

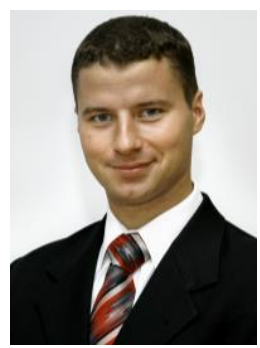

Janis Zakis (M'10 - SM'14) received B. Sc., M. Sc. and Dr. Sc. ing. in electrical engineering from Riga Technical University, Riga, Latvia, in 2002, 2004 and 2008 , respectively.

He is presently a Senior Researcher in the Institute of Industrial Electronics and Electrical Engineering, Riga Technical University.

He has over 30 publications and is the holder of the Utility Model in power converter design. His research interests include flexible ac transmission systems (FACTS), simulation of power systems, switching mode power converters, applied design of power converters and energy storage systems.

Riga Technical University, Institute of Industrial Electronics and Electrical Engineering.

Address: Azenes 12/1-515, LV-1048 Riga, Latvia;

E-mail: janis.zakis@rtu.lv, janis.zakis@ieee.org 